7?

columns not recommended by NICE; citalopram was the most common ( $n=10,53 \%$ ).

Twenty-two patients (43\%) were prescribed a psychotropic drug in our clinic and the most common choice in pregnancy was fluoxetine. This was used in 14 cases (14/22, 64\%). Amitryptiline was used in 4 cases $(4 / 22,18 \%)$ and the remaining 4 cases were each given nortryptiline, dosulepin, sertraline and chlorpromazine respectively (the latter two for breastfeeding women). Dosulepin was used in pregnancy for one patient despite not being recommended by NICE. This was a joint decision with that individual after considering the risks and benefits.

Whenever the prescription of an antidepressant was recommended, the pros and cons should have been discussed at length with the patient and their family, yet only $16 / 22$ cases ( $73 \%$ ) had clear documentation in the notes that this had taken place. Moreover, we were dismayed to realise that no patients were presented with written material to assist them in understanding the risks of prescribing psychotropic drugs in pregnancy or breastfeeding, despite NICE guidelines that such visual aids should be considered standard.

The audit suggests the need to improve training in primary and secondary care to reduce the number of pregnant and puerperal patients prescribed inappropriate psychotropics. It also highlights the dilemmas in providing women with appropriate written information regarding antidepressants in pregnancy and breastfeeding. The greatest concern for women is around possible teratogenic effects but the evidence base in this area is both rapidly changing and limited, with small-scale, descriptive studies that need to be carefully interpreted. Information from the UK National Teratology Information Service (www.nyrdtc.nhs.uk/ Services/teratology/teratology.html) is very helpful but is not presented in such a way that makes it easily accessible to patients

EWIS, G. \& DRIFE, J. (2004) Why Mothers Die 2000 -2002. The Sixth Report of Confidential Enquiries into Maternal Deaths in the United Kingdom. RCOG Press.

NATIONAL INSTITUTE FOR HEALTH AND CLINICAL EXCELLENCE (2007) Antenatal and Postnatal Mental Health. Clinical Management and Service Guidance. NICE (http://www.nice.org.uk/nicemedia/pdf/ CG45fullguideline.pdf)

*Baljinder Powar Specialist Registrar in Genera Adult Psychiatry, The Bradgate Mental Health Unit, Groby Road, Leicester LE3 9DZ, email: bspowar@ hotmail.com, Geraldine Swift Consultant in Consultation Liaison Psychiatry, Sarah Winston Staff Grade in Consultation, Liaison Psychiatry, Arrowepark Hospital, Wirral, Sanjay Khurm Specialist Registrar in General Adult Psychiatry Birmingham and Solihull Mental Health NHS FoundationTrust, Community DrugsTeam, Birmingham

doi: 10.1192/pb.33.1.37b

\section{Responsible medical officers and mental health review tribunals}

Doctors have been found wanting when it comes to understanding legislation relating to mental health review tribunals (Nimmagadda \& Jones, 2008). However, it is clear that Nimmagadda \& Jones (2008) also are lacking in legal knowledge with regard to the status of doctors as responsible medical officers (RMOs) at mental health review tribunals.

The question of the status of RMOs appearing before tribunals became so controversial that regional chairs of tribunals issued the following guidelines based on the old tribunal rules (J. Wright, personal communication, 2005).

1. The RMO does not have an automatic right to represent the authority.

2. The RMO is entitled to represent the authority under the provisions of rule 10 of the Mental Health ReviewTribunal Rules 1983. This is the only means by with the RMO can acquire full rights of representation.

3. The RMO may be permitted by the tribunal to take such part in the proceedings as the tribunal thinks proper pursuant to rule 22(4). This amounts to a form of 'quasi-representation' the circumstances and parameters being set by the tribunal.

4. Rule 22(1) states: 'the tribunal may conduct the hearing in such manner as it considers most suitable bearing in mind the health and interest of the patient and it shall, so far as appears to it appropriate, seek to avoid formality in its proceedings'

The authors make no mention of the potential harm to the therapeutic alliance between doctor and patient by the RMO adopting an adversarial, quasi-legal role at mental health review tribunals (Nimmagadda \& Jones, 2008).

I am not aware of any provision in the new rules coming into force on 3 November 2008 which alters the position (Office of Public Sector Information, 2008). The critical issue was whether the RMO was witness, representative of the responsible authority or both?

Finally, it is important to note that there are also financial risks in representing the responsible authority. Under rule 10 of the new rules, the tribunal may make a wasted costs order, which would be liable upon the individual representing the responsible authority (Office of Public Sector Information, 2008). This could occur owing to lapses leading to adjourned hearings for example.

If members are faced with complex high-risk tribunals where representation under the old rule 10 is necessary, my advice is to instruct a competent and skilled lawyer.

NIMMAGADDA, S. \& JONES, C. N. (2008) Consultant psychiatrists' knowledge of their role as representatives of the responsible authority at mental health review tribunals. Psychiatric Bulletin, 32, $366-369$.

OFFICE OF PUBLIC SECTOR INFORMATION (2008) The Tribunal Procedure (First-tierTribunal) (Health, Education and Social Care Chamber) Rules 2008. TSO (The Stationery Office).

Fareed Bashir Consultant Forensic Psychiatrist Greater Manchester West Mental Health NHS FoundationTrust, Adult Forensic Mental Health Service, Edenfield Centre, Bury New Road, Prestwich, Manchester M25 3BL, email: Fareed.Bashir@ gmw.nhs.uk

\section{doi: $10.1192 / \mathrm{pb} .33 .1 .38$}

Shortcomings of consultant psychiatrists representing their responsible authority at mental health review tribunals are clear (Nimmagadda \& Jones, 2008).

The Mental Health Act does not stipulate that the responsible medical officer must attend the tribunal, and, not uncommonly, the task is delegated to a junior doctor; occasionally, this is a senior house officer, who knows little psychiatry and nothing of the Mental Health Act. Such individuals are easy prey for solicitors representing patients, and if they (the doctors) are persuaded to say that the patient does not have a mental disorder of a nature or degree which warrants further detention, the tribunal has little choice but to discharge the patient from hospital, whatever their reservations about the case.

It seems to me vitally important that the responsible medical officer is responsible and attends the tribunal, as he is the most skilled in protecting the responsible authorities' best interests.

NIMMAGADDA, S. \& JONES, C. N. (2008) Consultant psychiatrists' knowledge of their role as representatives of the responsible authority at mental health review tribunals. Psychiatric Bulletin, 32 , $366-369$.

Alan C. Gibson Retired Consultant Psychiatrist, Late Member Mental Health ReviewTribunal, Woking, c/o Royal College of Psychiatrists, 17 Belgrave Square, London SW1X 8PG

\section{doi: 10.1192/pb.33.1.38a}

The responsible medical officer in the vast majority of cases is present at the hearing in the role of a witness. If they are to act as the representative of the responsible authority they are instructed to do this by their trust; this is usually in Section 37/41 cases. Therefore, Nimmagadda \& Jones (2008) are incorrect in their assertion that consultant psychiatrists, when giving evidence at a tribunal, 'act in most cases as 